\title{
Prevalence and associated risk factors of Strongyloides stercoralis infection in Lower Myanmar
}

\author{
Myo Pa Pa Thet Hnin Htwe Aung ${ }^{1 *}$, Akina Hino², Khine Mar Oo', Kyu Kyu Win', Haruhiko Maruyama²,
} Wah Win Htike ${ }^{1}$ and Eiji Nagayasu ${ }^{2}$

\begin{abstract}
Background: Strongyloidiasis is prevalent in Southeast Asian regions along with other soil-transmitted helminthiases, but only limited present-day data was available for Myanmar.

Methods: A prevalence survey for Strongyloides stercoralis infection was conducted among villagers in rural areas of three townships located in the Lower Myanmar during 2014-2016 by agar plate culture method in combination with specific identification by molecular assays. Risk factors associated with S. stercoralis infection were assessed by analyzing questionnaires obtained from study participants.

Results: Strongyloides stercoralis was identified in 40 out of 703 participants (5.7\% overall prevalence). The highest prevalence (14.4\%) was observed in Htantabin, while other two communities (Thabaung and Thanlyin) had much lower prevalence (2.2 and 2.5\%, respectively). Infection was relatively rare (1.2\%) in younger generations under 20 years compared to older generations (9.5\%). Even in Htantabin, none of the female residents under age $40(n=33)$ had infection. In adult Htantabin residents, those who answered that they do not wear shoes regularly had an elevated risk of infection (odds ratio $=2.50,95 \%$ confidence interval $=1.03-6.08$ ).

Conclusions: This study showed that there is still an on-going transmission of strongyloidiasis in Lower Myanmar. It is highly desirable that the soil should be free of fecal contamination by improving the management of fecal waste. Meanwhile, health education to promote shoe-wearing would be beneficial to reduce the risk of transmission, especially for those who have frequent and intense contact with soil.
\end{abstract}

Keywords: Strongyloides stercoralis, Prevalence, Myanmar, Agar plate culture, Molecular assays

\section{Background}

Strongyloides stercoralis has been described as one of the most neglected soil-transmitted helminths (STHs) among the neglected tropical diseases (NTDs) [1]. Although infection is acquired via contaminated soil, similar to major STHs, namely Ascaris lumbricoides, Necator americanus, Ancylostoma duodenale, and Trichuris trichiura, epidemiological information on $S$. stercoralis infection is scarce [2]. The primary route of infection of S. stercorailis is transdermal (infective larvae penetrate the skin), similar to hookworms ( $N$. americanus, $A$. duodenale), but

\footnotetext{
*Correspondence: MyoPaPaThetHnin@gmail.com

'Department of Microbiology, University of Medicine 1, No. 245 Myoma

Kyaung Street, Lanmadaw Township, Yangon, Myanmar

Full list of author information is available at the end of the article
}

differing from A. lumbricoides and T. trichiura, which are transmitted orally by ingestion of infective eggs.

Strongyloidiasis has a cosmopolitan distribution. Recently, it was estimated that at least 370 million are infected worldwide [3]. It affects $10-40 \%$ of the population in many tropical and subtropical countries [4]. In resource-poor countries with ecological and socioeconomic settings conducive to the spread of $S$. stercoralis, infection rates can be high, up to $60 \%$ [4].

Human strongyloidiasis is caused by two nematode species that belong to the genus Strongyloides: S. stercoralis is the most common and globally distributed human pathogen of clinical importance [5], while S. fuelleborni is found sporadically in Africa (S. fuelleborni fuelleborni) and Papua New Guinea (S. fuelleborni kellyi) [6].

(c) The Author(s). 2018 Open Access This article is distributed under the terms of the Creative Commons Attribution 4.0 International License (http://creativecommons.org/licenses/by/4.0/), which permits unrestricted use, distribution, and 
Although many cases of strongyloidiasis are asymptomatic, infection may be severe and even life-threatening in immunocompromised individuals. The unique ability of this nematode to replicate in the human host permits the cycles of autoinfection, leading to chronic disease that can last for several decades [6]. For treatment, ivermectin is more effective than thiabendazole or albendazole and considered the first-line therapy [7]. Myanmar currently has government-run mass drug administration (MAD) programs in place for both STH and lymphatic filariasis [8]. The former uses albendazole and the latter uses albendazole and diethylcarbamazine citrate [8]. Ivermectin, the first-line drug to treat strongyloidiasis, has not been used for the purpose of MDA.

Strongyloidiasis is frequently underdiagnosed, since many infections remain asymptomatic and conventional diagnostic tests based on parasitological examination are not sufficiently sensitive. The difficulty in diagnosing $S$. stercoralis infection is one of the reasons why up-to-date, accurate information on its geographic distribution in endemic regions and the total global burden is lacking. In Myanmar, there are few up-to-date data on the prevalence of Strongyloides and most of the previous studies were done by low-sensitive routine microscopic examinations.

During 2014-2016, we conducted an epidemiological survey to determine the prevalence of strongyloidiasis among villagers in rural areas of three divisions in Lower Myanmar. We used agar plate culture method in combination with specific identification of the isolated nematode by molecular assays. As a part of this project, molecular phylogenetic analyses of S. stercoralis worms isolated from these villagers were conducted [9]. In this paper, we described an epidemiological situation of strongyloidiasis in Lower Myanmar that was not included in our previous publication [9]. The results of this study will contribute to the development of appropriate strategies in the control of STH.

\section{Methods}

\section{Study design}

Cross-sectional descriptive study was carried out from January 2014 to January 2016. The study areas consisted of villages of Htantabin Township (Yangon Division), Thanlyin Township (Yangon Division), and Thabaung Township (Ayeyarwady Division). The locations of these sampling sites are shown in Fig. 1.

Htantabin Township is located on the western border of central Yangon Region, Myanmar. There are 59 village tracts in the township consisting of 230 villages. Overall population is 120,454 (2008). Thabaung is a town in the Pathein District, the Ayeyarwady Division of south-west Myanmar. There are 70 village tracts in the township consisting of 421 villages. Total population is 154,400 (2014). Thanlyin is a major port city of Myanmar,

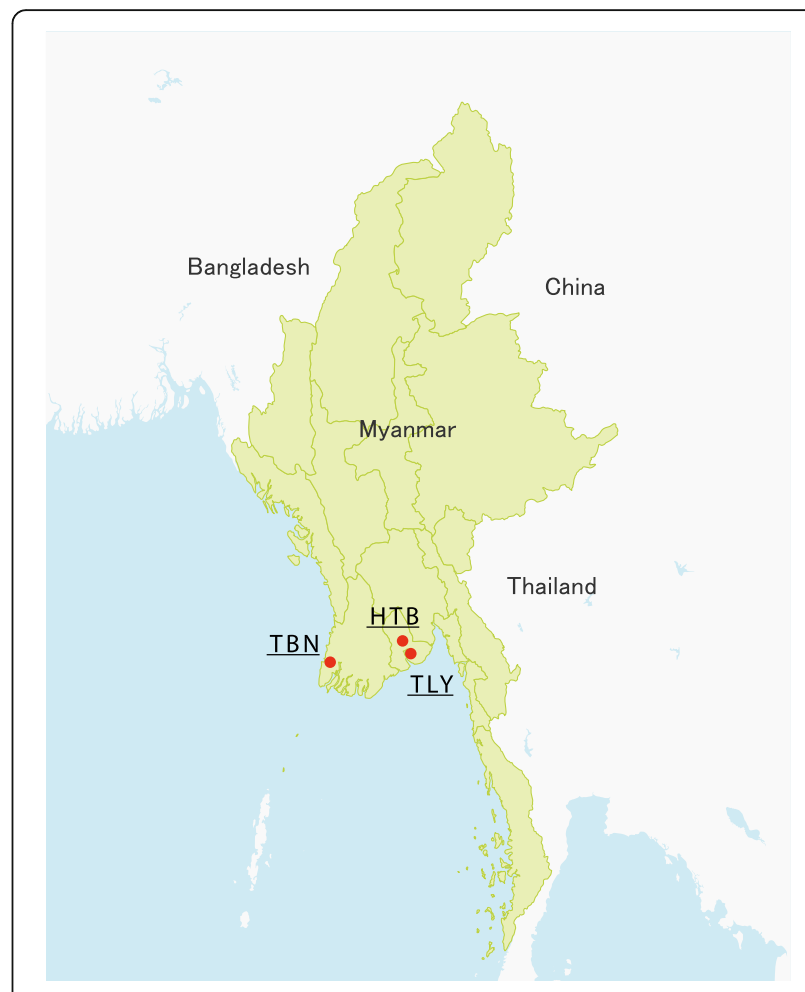

Fig. 1 Stool sampling locations in Lower Myanmar. HTB: Htantabin, TBN: Thabaung, and TLY: Thanlyin

located across Bago River from the city of Yangon. Thanlyin Township comprises 17 quarters and 28 village tracts. The total population is 181,000 (2009).

A multistage sampling method was used as the sampling procedure. Villages from each township were selected by the lottery method of randomization. Approximately 250 villagers per township were selected. Villagers who received any anti-helminthic treatment within 3 months prior to the study and villagers presenting with diarrhea at the time of sampling were excluded from the study.

\section{Collection of fecal specimens}

Plastic containers (clean, wide mouth screw-capped containers) and plastic bag were provided to those who agreed to participate. The participants were interviewed using structured questionnaires to obtain information such as their age, gender, education status, occupation, monthly income, regular wearing of shoes, and close contact with dogs (potential reservoir host). Overall, 703 villagers from three townships who provided both stool and completed a set of questionnaires were included in this study.

Stool specimens were transported using an air-conditioned car with inside temperature of about $25^{\circ} \mathrm{C}$. Transportation took about 2, 2, and $5 \mathrm{~h}$ from each sampling site (Htantabin, Thanlyin, and Thabaung, respectively) to the laboratory. 


\section{Fecal examinations}

The agar culture method for detection of $S$. stercoralis and worm lysate preparation procedures were based on previous publications $[9,10]$. Agar plates were cultured at room temperature (approximately $25^{\circ} \mathrm{C}$ ) for 4 days. Then, they were checked daily under a stereomicroscope to detect any nematode. Larvae or adult stages of nematodes found on the agar plates were picked up by a worm picker (fine needle made from tungsten) into polymerase chain reaction (PCR) tubes containing $10 \mu \mathrm{l}$ of worm lysis solution that was prepared by mixing 0.5 volume of proteinase $\mathrm{K}$ (> $600 \mathrm{mAU} / \mathrm{ml}$ solution, catalog no. 19131, Qiagen), 0.5 volume of $1 \mathrm{M}$ dithiothreitol (DTT), and 10 volumes of DirectPCR Lysis Reagent (Tail) (catalog no. 101-T, Viagen Biotech Inc.). The nematodes were lysed by incubation at $60^{\circ} \mathrm{C}$ for $20 \mathrm{~min}$. They were then incubated at $95^{\circ} \mathrm{C}$ for $20 \mathrm{~min}$ to inactivate proteinase $\mathrm{K}$. The tubes containing worm lysate were stored at $-30^{\circ} \mathrm{C}$ until used.

Presence of STHs other than S. stercoralis was assessed by direct wet mount microscopy.

\section{PCR and DNA sequencing}

A portion (935 bp) of $18 \mathrm{~S}$ rDNA gene which corresponds to positions -2-933 of AF279916 (GenBank) was amplified using a primer pair 988F ( $5^{\prime}$-ctcaaagattaagccatgc-3') and 1912R (5'-tttacggtcagaactaggg-3') [11]. The same primer, 1912R, was used for the sequencing reaction. We used a 333-bp region which spanned between positions 315-683 for identification of species as S. stercoralis [9].

\section{Statistical analysis}

After collection of data, data cleansing, data compilation, data processing, and data analysis were done by using statistical Excel and SPSS version 18.0.

\section{Results}

\section{Study population}

In total, 703 individuals from three townships were included in this study. The characteristics of the study population are summarized in Table 1. Among them, $342(48.6 \%)$ were male and $358(51.4 \%)$ were female. The median age of all participants was 28 years with a range of 1-105. In Htantabin, 31.4\% of the adult (equal or more than 20 years old) participants were farmers. On the other hand, none of the adult participants were farmers in Thabaung and Thanlyin.

\section{Strongyloidiasis prevalence determined by an agar plate culture method}

Nematodes were identified from $6.3 \%$ (44 out of 703) of the fecal samples by an agar plate culture method. Up to eight nematodes per sample were collected and subjected to sequencing analysis. The presence of S. stercoralis were confirmed in 40 out of 703 fecal samples, based on the partial 18S rDNA sequences. Therefore, the overall prevalence of strongyloidiasis among the study population was estimated to be $5.7 \%$. The highest prevalence was seen in Htantabin (28 out of 195, 14.4\%), followed by Thanlyin ( 6 out of $237,2.5 \%$ ) and Thabaung (6 out of 271,2.2\%). Prevalence by gender and age group is presented in Fig. 2. In Thabaung, none of the $132 \mathrm{fe}-$ male participants were infected. In Htantabin, no female participants below the age of 40 were infected.

\section{Risk factors for S. stercoralis infection}

A risk factor analysis was conducted only for Htantabin residents because of the low strongyloidiasis-positive case numbers, identified in the present study, in the other two communities. Being 20 years or more had the highest odds ratio (4.75) for infection, although the difference was considered not statistically significant $(p=$ $0.135)$. Other variables were tested only for adult participants, because there was only one positive case among participants below the age of 20 , and some variables such as monthly income were relevant only in adult population. Among the variables tested, only "not-wearing shoes regularly" was associated with $S$. stercoralis-positive test results with statistical significance (Table 2).

\section{Discussion}

Although chronic strongyloidiasis is often asymptomatic or accompanied only by low-grade gastrointestinal symptoms, it can also be fatal in immunocompromised or corticosteroid-treated individuals [12]. Awareness of strongyloidiasis is important, especially to prevent hyperinfection and disseminated strongyloidiasis. In Myanmar, however, the presence of S. stercoralis has not been well recognized. Direct wet mount microscopy

Table 1 Characteristics of the study populations

\begin{tabular}{llll}
\hline & Htantabin (HTB) & Thabaung (TBN) & Thanlyin (TLY) \\
& $n=195$ & $n=271$ & $13(1-105)$ \\
\hline Median age (range) & $45(2-84)$ & $13(2-68)$ & $101 / 136$ \\
Gender (male/female) & $102 / 93$ & $139 / 132$ & 100,000 \\
Median monthly income (kyats) & 150,000 & 196,000 & 0 \\
Proportion (\%) of farmer among adult participants & 31.4 & 0 & 0 \\
\hline
\end{tabular}



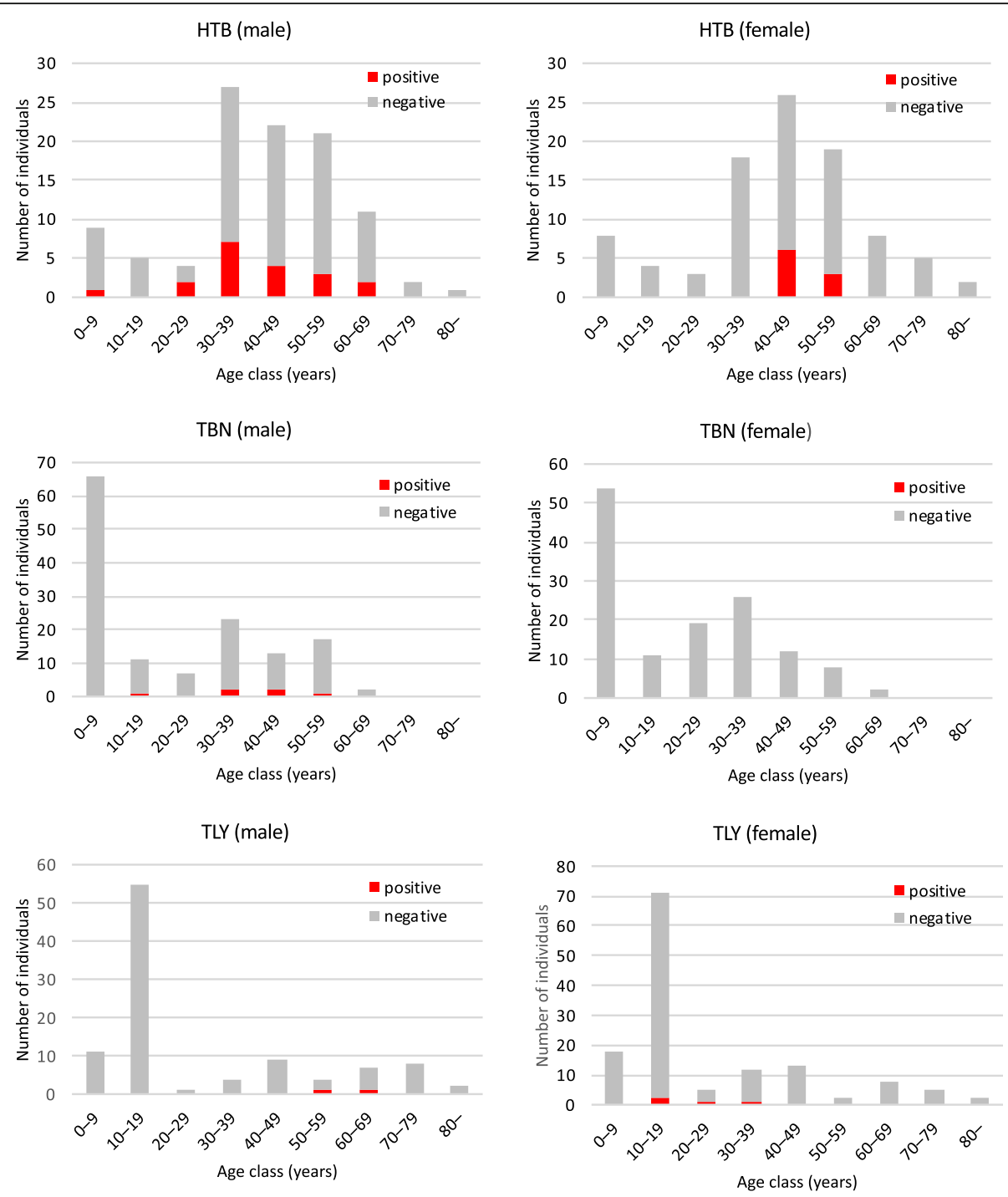

Fig. 2 Number of S. stercoralis positive and negative individuals by age group

and Kato-Katz technique are commonly used in prevalence studies of geohelminthes, but they are inadequate for S. stercoralis detection.

In this study, we used the agar plate culture, that is one of the most sensitive parasitological methods to detect $S$. stercoralis infection $[13,14]$, and the overall prevalence of strongyloidiasis among our study population in Lower Myanmar was found to be $5.7 \%$. It was higher than the prevalence reported from previous studies, such as 3.8\% of children from Yangon Children Hospital in 1987 [15], $0.8 \%$ of patients attending No. 2 Military Hospital during 2000-2001 [16], and 1.67\% of children from North Okkalapa Township, Yangon, in 2004 [17]. However, our prevalence was lower than the values reported from some older studies, such as 15 and 13\% among miners working at Mawlamyaing Antimony Mine and No. 1 copper project at Monywa, respectively, in 1981 [18].
The overall prevalence of $5.7 \%$ is rather low compared to recent prevalence reported from other Southeast Asian countries, such as Lao PDR (41.0\%) [19] and Cambodia (21.0\%) [20]. This may be due to the relatively large proportion of non-farmers included in our study.

Among the three townships, Htantabin had the highest prevalence (14.4\%). Even there, none of the female participants under the age of 40 were infected ( 0 out of 33). This was a great contrast to the male participants belonging to the same age groups (10 out of $45 ; 22.2 \%$ ). This may indicate relatively low chance of transmission at home considering that males and females share the same domestic environment. We hypothesize that the higher prevalence in males might be due to more chance for them to acquire infection during outdoor activities such as farming compared to females who tend to spend more time to carry out their works at home. 
Table 2 Correlation of S. stercoralis infection and sociodemographic and other characteristics

\begin{tabular}{|c|c|c|c|}
\hline Variable & No. Infected & Odds ratio $[95 \% \mathrm{Cl}]$ & $p$ \\
\hline \multicolumn{4}{|l|}{ Aget } \\
\hline$<20$ years & $1 / 26(3.8 \%)$ & & \\
\hline$\geq 20$ years & $27 / 169$ (16.0\%) & $4.75[0.62-36.58]$ & 0.135 \\
\hline \multicolumn{4}{|l|}{ Gender } \\
\hline Female & $9 / 72(12.5 \%)$ & & \\
\hline Male & $18 / 70(25.7 \%)$ & 2.06 [0.87-4.89] & 0.14 \\
\hline \multicolumn{4}{|l|}{ Occupation } \\
\hline Other than farmer & 15/116 (12.9\%) & & \\
\hline Farmer & $12 / 53(22.6 \%)$ & $1.97[0.85-4.57]$ & 0.119 \\
\hline \multicolumn{4}{|l|}{ Monthly income } \\
\hline$\geq 150 \mathrm{~K}$ kyats & 14/94 (14.9\%) & & \\
\hline$<150 \mathrm{~K}$ kyats & 13/75 (17.3\%) & $1.20[0.52-2.73]$ & 0.679 \\
\hline \multicolumn{4}{|l|}{ Education } \\
\hline Less than middle school & 23/128 (18.0\%) & & \\
\hline Middle school or more & $4 / 41(9.8 \%)$ & $0.49[0.16-1.52]$ & 0.326 \\
\hline \multicolumn{4}{|l|}{ Regular wearing of shoes } \\
\hline Yes & 17/115 (14.8\%) & & \\
\hline No & 10/37 (27.0\%) & 2.50 [1.03-6.08] & $0.045^{*}$ \\
\hline \multicolumn{4}{|l|}{ Close contact with dogs } \\
\hline No & 24/115 (20.9\%) & & \\
\hline Yes & $3 / 30(10.0 \%)$ & $0.53[0.15-1.90]$ & 0.428 \\
\hline \multicolumn{4}{|l|}{ Presence of other STHs } \\
\hline No & $24 / 148(16.2 \%)$ & & \\
\hline Yes & $3 / 21(14.3 \%)$ & $0.86[0.24-3.15]$ & 1.000 \\
\hline
\end{tabular}

tData from all age groups, otherwise data from only adults (20 years old or more) were used

${ }^{*} p<.05$

No. number, $\mathrm{Cl}$ confidence interval, STH soil-transmitted helminths

Persons who do not wear shoes regularly had higher risk of infection. The association of failure to wear shoes and S. stercoralis infection has been reported in other studies such as those conducted in Peruvian Amazon [21] and Lao PDR [22]. There is an urgent need to improve environmental sanitation (reducing fecal contamination in soil) to prevent soil-to-skin transmission of $S$. stercoralis. More investigation is needed to elucidate the degree and mechanisms of fecal contamination of the soil in these areas. Meanwhile, education to emphasize the wearing of shoes should be given especially to those who have frequent and intense contact with soil, such as farmers.

We would like to conduct similar studies in other areas of Myanmar, and we hope that such studies will be effectively used to develop the appropriate strategies for the control of STH including strongyloidiasis.

\section{Conclusions}

S. stercoralis infection is still prevalent among villagers in some rural areas of the Lower Myanmar. Healthcare professionals need to be aware of potential S. stercoralis infection among the residents living in these endemic areas, especially when treating them with corticosteroids for a variety of medical reasons, to avoid the risk of life-threatening hyper-infection. Health education and motivation for good hygienic practices, improved sewage disposal techniques, and the habit of wearing of shoes would also be salient factors to reduce the risk of infection.

\section{Abbreviations}

DTT: Dithiothreitol; NTDs: Neglected tropical diseases; PCR: Polymerase chain reaction; rDNA: Ribosomal deoxyribonucleic acid; STHs: Soil-transmitted helminths

\section{Acknowledgements}

We express our gratitude to those who supported our work: Professor $U$ Thet Khaing Win (Rector of the University of Medicine 1), Professor U Than Cho (former Rector), Colonel Kyaw Soe (Prof. and Head of Preventive and Social Medicine Department; Defense Service Medical Academy) and their staff, the chief of Thabaung Paper Factory and their staff, Sayardaw U Ottamasara of Thabawa Dhamma Meditation Center, and Daw Cho Cho Win and volunteers. Special thanks goes to Dr. Tin Tin Htwe, Dr. Soe Moe Thu Win, Dr. Okka Kyaw, and the laboratory technicians of Microbiology Department, University of Medicine 1 for their excellent support of this work. Our special gratitude goes to all the study population for their whole-hearted commitment to the present study.

\section{Funding}

This work was partially supported by a JSPS Grant-in-Aid for Scientific Research (c): grant no 17K08809 and a grant from the Japanese Agency for Medical Research and Development (AMED), Emerging/Re-emerging Infectious Diseases Project of Japan: grant no. 5fk0108046h0003.

Availability of data and materials

All essential data generated or analyzed during this study were included in this article.

\section{Authors' contributions}

MPPTHHA conceived and designed the study. AH and EN developed PCR/ sequencing protocols. MPPTHHA, KMO, KKW, and WWH performed field sampling procedures. MPPTHHA wrote the initial draft. KKW, MH, and EN revised the manuscript. All authors read and approved the final manuscript.

\section{Ethics approval and consent to participate}

The procedures were approved by the ethical committee of the University of Medicine 1, Yangon. The nature and the objectives of the study were explained to the villagers. Written informed consent was provided by the participants or by parents/guardians (if the participants were under 18 years of age). We provided anthelminthic to all the participants.

\section{Consent for publication}

Not applicable.

\section{Competing interests}

The authors declare that they have no competing interests.

\section{Publisher's Note}

Springer Nature remains neutral with regard to jurisdictional claims in published maps and institutional affiliations.

\section{Author details}

${ }^{1}$ Department of Microbiology, University of Medicine 1, No. 245 Myoma Kyaung Street, Lanmadaw Township, Yangon, Myanmar. ${ }^{2}$ Division of 
Parasitology, Department of Infectious Diseases, Faculty of Medicine, University of Miyazaki, 5200 Kihara, Kiyotake, Miyazaki 889-1692, Japan.

Received: 31 October 2018 Accepted: 2 December 2018

Published online: 18 December 2018

\section{References}

1. Olsen A, van Lieshout L, Marti H, Polderman T, Polman K, Steinmann P, et al Strongyloidiasis-the most neglected of the neglected tropical diseases? Trans R Soc Trop Med Hyg. 2009;103:967-72.

2. Hall A, Conway DJ, Anwar KS, Rahman ML. Strongyloides stercoralis in an urban slum community in Bangladesh: factors independently associated with infection. Trans R Soc Trop Med Hyg. 1994;88:527-30.

3. Bisoffi Z, Buonfrate D, Montresor A, et al. Strongyloides stercoralis: a plea for action. PLoS Negl Trop Dis. 2013;7:e2214.

4. Schar F, Trostdorf U, Giardina F, Khieu V, Muth S, Marti H, et al. Strongyloides stercoralis: global distribution and risk factors. PLoS Negl Trop Dis. 2013;7:e2288.

5. Bethony J, Brooker S, Albonico M, Geiger SM, Loukas A, Diemert D, et al. Soil-transmitted helminth infections: ascariasis, trichuriasis, and hookworm. Lancet. 2006:367:1521-32.

6. Grove Dl. Human strongyloidiasis. Adv Parasitol. 1996;38:251-309.

7. Zaha O, Hirata T, Kinjo F, Saito A, Fukuhara H. Efficacy of ivermectin for chronic strongyloidiasis: two single doses given 2 weeks apart. J Infect Chemother. 2002:8:94-8.

8. Dunn JC, Bettis AA, Wyine NY, et al. A cross-sectional survey of soiltransmitted helminthiases in two Myanmar villages receiving mass drug administration: epidemiology of infection with a focus on adults. Parasit Vectors. 2017:10:374

9. Nagayasu E, Aung M, Hortiwakul T, Hino A, Tanaka T, Higashiarakawa M, et al. A possible origin population of pathogenic intestinal nematodes, Strongyloides stercoralis, unveiled by molecular phylogeny. Sci Rep. 2017;7:4844.

10. Arakaki T, Iwanaga M, Kinjo F, Saito A, Asato R, Ikeshiro T. Efficacy of agarplate culture in detection of Strongyloides stercoralis infection. J Parasitol. 1990;76:425-8

11. Holterman M, van der Wurff A, van den Elsen S, van den Elsen S, van Megen $\mathrm{H}$, Bongers T, et al. Phylum-wide analysis of SSU rDNA reveals deep phylogenetic relationships among nematodes and accelerated evolution toward crown clades. Mol Biol Evol. 2006;23:1792-800.

12. Buonfrate D, Formenti F, Perandin F, Bisoffi Z. Novel approaches to the diagnosis of Strongyloides stercoralis infection. Clin Microbiol Infect. 2015;21: 543-52.

13. Jongwutiwes $S$, Charoenkorn $M$, Sitthichareonchai $P$, Akaraborvorn $P$, Putaporntip C. Increased sensitivity of routine laboratory detection of Strongyloides stercoralis and hookworm by agar-plate culture. Trans R Soc Trop Med Hyg. 1999;93:398-400.

14. Sato Y, Kobayashi J, Toma H, Shiroma Y. Efficacy of stool examination for detection of Strongyloides infection. Am J Trop Med Hyg. 1995;53:248-50.

15. Mar A. The profile of common intestinal helminthiasis in children admitted to Rangoon Children's hospital (Master's thesis). Institute of Medicine 1. In: Rangoon; 1987.

16. Than A, Kyaw KT, Wah HN, Saw T, Htut Y. Diagnosis methods for intestinal parasites. Myanmar Health Res Congress. 2001;2001:67.

17. Nyunt WW. Common intestinal helminths in apparently healthy children attending the pre-primary school in North Okkalapa Township (Master's thesis). University of Medicine 2, Yangon, 2004

18. Lwin KO, Zaw M. Geohelminths in Moulmein and Monywa. Burma Med J. 1981;28:121-5

19. Laymanivong $S$, Hangvanthong $B$, Insisiengmay $B$, Vanisaveth $V$, Laxachack $P$, Jongthawin J, et al. First molecular identification and report of genetic diversity of Strongyloides stercoralis, a current major soil-transmitted helminth in humans from Lao People's Democratic Republic. Parasitol Res. 2016;115:2973-80

20. Khieu V, Schar F, Marti H, Bless PJ, Char MC, Muth S, et al. Prevalence and risk factors of Strongyloides stercoralis in Takeo Province, Cambodia. Parasit Vectors. 2014;7:221.

21. Yori PP, Kosek M, Gilman RH, Cordova J, Bern C, Chavez CB, et al. Seroepidemiology of strongyloidiasis in the Peruvian Amazon. Am J Trop Med Hyg. 2006;74:97-102.

22. Senephansiri $P$, Laummaunwai $P$, Laymanivong $S$, Boonmar T. Status and risk factors of Strongyloides stercoralis infection in rural communities of Xayaburi Province, Lao PDR. Korean J Parasitol. 2017;55:569-73.

Ready to submit your research? Choose BMC and benefit from:

- fast, convenient online submission

- thorough peer review by experienced researchers in your field

- rapid publication on acceptance

- support for research data, including large and complex data types

- gold Open Access which fosters wider collaboration and increased citations

- maximum visibility for your research: over $100 \mathrm{M}$ website views per year

At $\mathrm{BMC}$, research is always in progress.

Learn more biomedcentral.com/submissions 